\title{
Why a new sport science journal?
}

\author{
Martin Kopp ${ }^{1, *}$ \\ 1 Department of Sport Science, University of Innsbruck, Innsbruck, Austria \\ * Corresponding author: Department of Sport Science, University of Innsbruck, Fürstenweg 185, A-6020 Innsbruck, Austria, \\ Tel.: (43) 512-507-45851, Fax: (43) 512-507-45999, E-Mail: Martin.Kopp@uibk.ac.at
}

\section{EDITORIAL}

Article History:

Published $1^{\text {st }}$ March 2016

Editor-in-Chief:

Martin Kopp

University of Innsbruck, Austria

\section{ABSTRACT}

This "inaugural" editorial summarizes conversations which have led to the development of the journal "Current Issues in Sport Science (CISS)". The main reason for CISS was, that - despite developing rapidly - sport science has a lack of "full scope sport science journals". Furthermore, sport science as an interdisciplinary discipline I believe can benefit from a reinforced identity through mutual acceptance of all streams. This new journal aims to address this need for more inclusive outlets for sport science. The last section of this editorial describes methods of publication concluding that open access $(O A)$ publication, which guarantees free use and rapid distribution of all published work, is the best approach for this Journal.

Citation:

Kopp, M. (2016). Why a new sport science Journal? Current Issues in Sport Science, 1:002. doi: 10.15203/CISS_2016.002

Sport science has developed rapidly during the last three decades (Reilly, 2008a). Besides the early emphasis focusing on performance related issues the last decades have brought an increasing focus on health challenges. A short PubMed search using the keywords "sport or exercise or physical activity" with the year [1985/1995/2005/2015 (01.01-31.12)] revealed an increase of publication frequency in our field, which has roughly doubled from decade to decade $(1985: 6645 ; 1995: 10284 ; 2005$ : 20876; 2015: 42917). When approaching the ISI Web of Knowledge citation reports, the category SPORT SCIENCES is comprised of 81 indexed journals in the currently available year 2014. Out of these, eight of the journals seem to cover the full scope of sport science although four have a strong tendency towards physiology and medicine using "medicine" in the title. One is published in French (SCIENCE \& SPORTS) which limits the potential distribution of knowledge published in this journal. Thus at the moment, only three (JOURNAL OF SPORTS SCIENCES, EUROPEAN JOURNAL OF SPORT SCIENCE, RESEARCH QUARTERLY FOR EXERCISE AND SPORT) of the 81 indexed journals in the category SPORT SCIENCES focus on all aspects of sport science and therefore, cover the full scope of the field of this science (Reilly, 2008b). In fact this lack of "full scope sport science journals" was the strongest and most urgent matter discussed by the Sport Scientific Societies of Austria and Switzerland. Therefore a new publication option addressing the full scope of sport science research with the CURRENT ISSUES IN SPORT SCIENCE (CISS) journal has been developed.

\section{Do we need integrative sport science?}

The low number of integrative (i.e. "full scope") sport scientific journals raises the question about underlying drivers for an ongoing separation in our field. Within university curriculums teaching is often separated into performance related issues, health issues, physical education and sport management. This seems to be a manageable approach and most of the study areas are delivered by sport scientific departments, who try to offer potential students educational opportunities to specialize along their interests. But in research terms, the invisible line between sport and exercise science might be discussed as a real challenge in the field, dividing researchers who are focusing on the - in their opinion - "real" sport (Hale, 2008; Nevill, Atkinson, \& Hughes, 2008; Williams, Hardy, \& Mutrie, 2008) from those who are focusing on increasing physical activity as the perhaps most important health challenge of modern western societies (Trost, Blair, \& Khan, 2014). Over a period of decades, however, this division has produced some nice names of scientific university departments, where colleagues omitted the name sport and went on with health/exercise/human movement/kinesiology sciences. Yet in my opinion, by going back to a broad definition of sport, one might be able to collect all these directions under the umbrella of sport science thereby reducing division and increasing integration.

Despite the necessity of specializing in each scientific discipline, in sport science there seems to be more separation tendencies than in any other scientific field. From a meta-perspective 
influenced ironically from a psychological point of view, one might observe relatively low self-identity followed by low selfesteem in the field of sport science. This is because many sport scientists try and connect to another broad science paradigm such as physics or medicine instead in an attempt to be more accepted in their advanced specialization. Often, in my experience this engagement seems to be combined with a reduced interest in other fields of sport science affecting the collaborative and integrative approach that sport science could have. The reason behind this as well as for the small number of journals focusing on the whole field of sport science might be found in the history of this science itself. Being partly developed out of many parent sciences, the field and scope of sport science is indeed wide and diverse. When working in a discipline with a specific scope such as "sport economy" or "high altitude sports medicine" it often seems easier to look for shelter in the arms of the parent science (i.e., economics or medicine) than to collaborate with those areas of science which are different despite sharing a common name "sport". However, I believe we should thoroughly maintain and further develop sport science as a distinct and separate field of science. Sport science has to keep in mind its identity and to clarify to be one scientific brand. Neglecting this would consequently lead to a shutdown of the category SPORT SCIENCES in the ISI Web of Knowledge citation reports and necessitate the linking of sport and exercise science to other mother science categories. Therefore, one might reflect, that - despite being very interdisciplinary and of course benefitting from this - sport science needs to reinforce its identity by strengthening its unity and togetherness. Accordingly, optimizing the mutual acceptance of all streams might be the most important step in this direction. This definitively does not mean to stop looking beyond one's own nose (Hagger, 2006). Thus I hope I have provided a strong argument to develop a new and integrative publication in our field with CURRENT ISSUES IN SPORT SCIENCE (CISS) and we strongly encourage you to address our new journal for the dissemination of your sport science research.

\section{Do we need new approaches in publishing?}

The fast growth of the sport science field has led an aforementioned increase of publications, however, the traditional paper based approach to dissemination has led to a first wake-up call, when sport scientists noticed, that hardly anybody recognized their fascinating research reports or books stored in the libraries of their universities. A second wake-up call followed especially for scientists from non-english-speaking countries, who realized the same trend despite having already started to publish their work in regional scientific journals. These wakeup calls have led to greater on-line presence to encourage truly international publications.

However, publishing in the established international scientific journals has brought up a new issue in the last few decades. Articles published in scientific journals of famous publishers are usually not free for everybody and time from acceptance until publication of an article may last several months. To make it more difficult, one needs a library- and subscription-system or has to pay by article to assess actual knowledge in the field, which implies a potential disadvantage for researchers or interested people living in so-called developing countries or working as independent researchers or scientific journalists. Thus, the one and only approach which can solve this problem seems to be the open access (OA) initiative, which guarantees free use and rapid distribution of all published work for all potential readers with internet access. Therefore, the approach of CISS fully complies with the Budapest Open Access Initiative (BOAI) and reaffirms the aspiration to achieve scientific results as an "unprecedented public good" and to "accelerate research, enrich education, share the learning of the rich with the poor and the poor with the rich, make this literature as useful as it can be, and lay the foundation for uniting humanity in a common intellectual conversation and quest for knowledge" (BOAl, 2016). However, this highlights the problem for us researchers that, despite the fact we are agreeing with a free dissemination of scientific knowledge, the costs for publishing in OA-journals are left with us personally and our departments or universities. And honestly, one can understand the plight of colleagues who are refusing to pay OA fees for getting their own work published when they earlier received money (i.e. by selling books) for the same work. A solution of this problem might be found in the funding of university libraries. OA has the potential to reduce the subscription costs for traditional journals and our libraries and university leading teams might be well advised to shift their budget partly to support OA-publication. As the pros were more convincing, CURRENT ISSUES IN SPORT SCIENCE (CISS) has stated a clear commitment to publish all material as $\mathrm{OA}$-articles by trying to keep the payment from authors as low as possible.

Thus in summary CURRENT ISSUES IN SPORT SCIENCE (CISS) is a new journal with the aim to cover the entire field of sport science to celebrate the identity of a very interdisciplinary field of scientific activities by providing a modern open access approach for publishing high quality research. In addition to reports of original research, the journal publishes review articles, reports (including case studies, short communications, theoretical or practical reflections), invited commentaries and target articles (the first one being Vickers, 2016). Being divided into the sections biology \& medicine, biomechanics \& informatics, movement \& exercise science, pedagogy \& history, psychology \& philosophy and sociology \& economics and being provided with a section editor for each of these, who is responsible for the final decision of acceptance together with the Editor-inChief after rigorous peer-review, we think, we have developed a framework for furthering sport science research paradigms. My optimism in having the chance to improve the field of sport science with CISS is reliant on the Advisory Board, full of excellent and like-minded researchers.

We are really looking forward to receiving your manuscripts! 


\section{Acknowledgements}

The author is grateful for being brought back down to earth by the helpful 'physiological' comments from Michael Kennedy, $\mathrm{PhD}$, University of Alberta, Canada.

\section{Competing Interests}

The author's role for CISS is Editor-in-Chief (2016-2020) and Founding Editor (2015).

\section{References}

BOAI (2016). Budapest open access initiative. Retrieved 23 $3^{\text {rd }}$ February 2016 from http://www.budapestopenaccessinitiative.org/

Hagger, M. S. (2006). Meta-analysis in sport and exercise research: Review, recent developments, and recommendations. European Journal of Sport Science, 6(2), 103-115. 10.1080/17461390500528527

Hale, T. (2008). History of developments in sport and exercise physiology: A. V. Hill, maximal oxygen uptake, and oxygen debt. Journal of Sports Sciences, 26(4), 365-400. 10.1080/02640410701701016

Nevill, A., Atkinson, G., \& Hughes, M. (2008). Twenty-five years of sport performance research in the Journal of Sports Sciences. Journal of Sports Sciences, 26(4), 413-426. 10.1080/02640410701714589

Reilly, T. (2008a). Journal of Sports Sciences: The first 25 years. Journal of Sports Sciences, 26(4), 347-348. 10.1080/02640410 701875349

Reilly, T. (2008b). The international face of sports science through the window of the Journal of Sports Sciences - with a special reference to kinanthropometry. Journal of Sports Sciences, 26(4), 349-363. 10.1080/02640410701429824

Trost, S. G., Blair, S. N., \& Khan, K. M. (2014). Physical inactivity remains the greatest public health problem of the $21^{\text {st }}$ century: Evidence, improved methods and solutions using the "7 investments that work" as a framework. British Journal of Sports Medicine, 48(3), 169-170. 10.1136/bjsports-2013-093372

Vickers, J. N. (2016). Origins and current issues in Quiet Eye research. Current Issues in Sport Science, 1:101. 10.15203/CISS_2016.101

Williams, A. M., Hardy, L., \& Mutrie, N. (2008). Twenty-five years of psychology in the Journal of Sports Sciences: A historical overview. Journal of Sports Sciences, 26(4), 401-412. 10.1080/02640410701765631 
